\title{
A Multidisciplinary Pharmacological Approach for Management of Osteoporosis Affecting Implant-Bone Healing - A Review
}

\author{
Dr. Keerthi $\mathrm{GK}^{1^{*}}$, Dr. M.V.Saiteja ${ }^{2}$, Dr. Dilip Rajasekhar Maddirela M.Sc, $\mathrm{PhD}^{3}$, Dr. Abbasi Begum Meer Rownaq $\mathrm{Ali}^{4}$
}

\author{
${ }^{1}$ M.D.S Prosthodontist, Ajman University, University Street, Al jerf 1 - Ajman - United Arab Emirates \\ ${ }^{2}$ Prosthodontist, Tirupathi, India \\ ${ }^{3}$ Senior Scientific Writer, Free Lancer, Tirupathi, India \\ ${ }^{4}$ M.D.S, Prosthodontist, Lecturer, Riyadh Elm University, Saudi Arabia
}

DOI: $\underline{10.36348 / \text { sjodr.2020.v05i06.001 }}$

| Received: 21.05.2020 | Accepted: 31.05.2020 | Published: 06.06.2020

*Corresponding author: Dr. Keerthi GK

\section{Abstract}

A multidisciplinary approach to medicine is something that is becoming more popular and widespread today. The combination of multiple health care disciplines can be extremely beneficial to progress an individual's healing at a more rapid pace than relying only on one area for assistance. Amongst the most popular medical disciplines today, ancient ayurvedic medicine is most popular that many patients are seeking to relieve their ailments not only in India but also in other parts of the world. On the other hand, dental implants are the modern treatment modality that is popular for management of edentulism. However, majority of the elderly patients receiving dental implants are systemically associated with bone disorders that affect bone healing which in turn interferes with osseointegration. Here this review focuses on various pharmacological agents (including ayurvedic) for management of osteoporosis. For the review, data was collected from recently published articles (2001-2018) and multidisciplinary treatment options available for osteoporosis are summarized and reviewed.

Keywords: Bone healing, Osseointegration, Osteoporosis, Pharmacology, Ayurveda.

Key messages: Osteoporosis being one of the risk factor for implant placement should be managed with pharmacological agents while considering the implant factors and the role of multidisciplinary approach should never be underestimated and more studies are suggested in this respect.

Copyright @ 2020: This is an open-access article distributed under the terms of the Creative Commons Attribution license which permits unrestricted use, distribution, and reproduction in any medium for non-commercial use (NonCommercial, or CC-BY-NC) provided the original author and source are credited.

\section{INTRODUCTION}

Osseointegrated implants have become a routine and reliable treatment for edentulous patients [1]. Despite of their importance and many advances in techniques, materials, and implant designs, the risk of implant failure remains a significant concern for both dentists and patients. The success of dental implant relies mainly on successful osseointegration [2], which is the direct structural and functional connection between living bone and the dental implant surface [3]. The process of osseointegration around implants is similar to the biological events occurring during bone repair and fracture healing. This involves 4 phases: homeostasis, inflammation, proliferation, and remodeling. The phases of homeostasis and inflammation are mainly related to wound healing, whereas proliferation and remodeling are related primarily to bone metabolism. Metabolic activity of bone plays a crucial role in the success of osseointegration [4], and disturbance of bone metabolism can have a negative impact on bone healing and implant osseointegration. Therefore, pharmacological agents interfering with bone metabolism can affect osseointegration and ultimately implant survival [5, 6]. Apart from the conventional pharmacological agents, alternatives such as natural and herbal therapies are gaining worldwide recognition. The herbal medicine available in the market, Lakshadi Guggul (LG) is a combination of many herbal products including Cissus quadrangularis, Withania somnifera, Azadirachta indica, Sida alba and Terminalia arjuna which are proved to be effective in bone healing, calcium deposition and management of osteoporosis.

\section{Osteoporosis}

Osteoporosis is characterized by low bone mass, structural deterioration, and porous bone, which are associated with higher fracture risk [7]. Bone loss related to declining estrogen levels, increases fracture risk in postmenopausal women, who make up the majority of osteoporosis cases. Epidemiological data 
show that osteoporosis is increasing among the elderly female and male (>50 years) population. A striking characteristic of the osteoporotic condition is the severe reduction of bone quality and quantity which is suggested to be detrimental for bone-implant integration [8]. Additionally, the biomechanical characteristics of osteoporotic bone do not offer proper stability to implants, being similar to type-IV bone (Lekholm \& Zarb classification) in which a decreased clinical fixation of implants has been clearly demonstrated [9]. Though, this condition is not an absolute contraindication for implant treatment, decreased osteogenic capacity of bone in an osteoporotic condition [10] can be considered as a possible risk factor for implant failure [11-13]. Such a risk of implant failure in osteoporotic bone is hypothetically related to various factors that compromise bone-implant healing and potentially impair osseointegration. However, the search for improved bone regeneration in challenged conditions has lead to continuing evolution of modern dental implants.

\section{Pharmacological Management of Osteoporosis}

Many medications such as bisphosphonates, estrogen replacement therapy, vitamin $\mathrm{D}$, calcitonin and parathyroid hormone replacements [8] that are approved for management of osteoporosis have their positive effect on bone healing.

Bisphosphonates [14] are anti-resorptive agents for management of cancer and osteoporosis. Bisphosphonates act by inhibiting osteoclastic activity and bone resorption. However, orally administered bisphosphonates may cause irritation in the esophagus. Rapid intravenous administration of parenteral bisphosphonates may cause renal toxicity.

Other common side effects are fatigue, gastrointestinal reaction, mucosal ulceration, atypical bone fractures and osteonecrosis [15] of the jaw. However, conflicting evidence is found on the effects of bisphosphonates on osseointegration. For instance, Fugazzatto et al., [16] found that a history of oral bisphosphonates for 3 years did not lead to osteoradionecrosis of jaw (ONJ) after implant placement. Similarly, in a parallel-group controlled trial involving patients who had undergone surgical placement of dental implants, Jeffcoat [17] concluded that there was no significant difference between the incidence of ONJ among patients taking bisphosphonates and the control group. Also, Grant et al., [18] found no significant difference in treatment results between patients with and without oral bisphosphonates during implant treatment and no patients developed ONJ after implant treatment. Finally, after a systematic review, Madrid and Sanz [19] concluded that a patient receiving oral bisphosphonates for less than 5 years is "safe" to undergo dental procedures, specifically dental implants. In summary, there is insufficient data to suggest that implant placement should be avoided in patients receiving bisphosphonates. Nonetheless, dental practitioners who place implants must to be aware of the risk of treating patients who are under bisphosphonate therapy, oral or intravenous [6].

Estrogen replacement therapy [8] is a wellknown hormonal medication, used to prevent and treat dementia and osteoporosis in postmenopausal women. Estrogen is very effective in reducing age related bone loss and bone fracture risk. Raloxifene, a selective estrogen receptor modulator, is approved for treating postmenopausal osteoporosis, and is effective at reducing vertebral fractures only. Raloxifene [20] is commonly associated with increased vasomotor symptoms. It is associated with an increased risk of venous thromboembolism. The best candidates for raloxifene are postmenopausal women with osteoporosis who are unable to tolerate bisphosphonates, have no vasomotor symptoms or history of venous thromboembolism, and have a high breast cancer risk score. Bazedoxifene is a selective estrogen receptor modulator more recently approved for use for the prevention of osteoporosis as part of a combination therapy with conjugated estrogen Vitamin D supplementation is also used to treat osteoporosis. Vitamin D increases calcium absorption, improves bone mineral density and may reduce the bone fracture risk [8].

Calcitonin is a hormonal therapy, used to treat postmenopausal osteoporosis, hypercalcemia, Paget's disease, and other bone related conditions such as bone metastases. Calcitonin inhibits osteoclasts activity and increases bone mineral density [21]. Calcitonin nasal spray is an antiresorptive agent approved for the treatment of postmenopausal osteoporosis. It has been shown to decrease the occurrence of vertebral compression fractures only. Although calcitonin has modest analgesic properties in the setting of acute and chronic vertebral compression fracture, it is not considered first-line treatment for osteoporosis because more effective medications are available. There have also been reports of increased cancer rates associated with use of calcitonin [22].

Teriparatide [21] is a recombinant human parathyroid hormone with bone anabolic activity. Teriparatide is approved for the treatment of postmenopausal women with severe bone loss, men with osteoporosis who have high risk of fracture, and individuals whose condition has not improved with bisphosphonate therapy.

Denosumab [23] is a human monoclonal antibody that inhibits the formation and activity of osteoclasts by blocking receptor activator of nuclear factor kappa B ligand. In a dose of $60 \mathrm{mg}$ given subcutaneously every six months for three years, it 
significantly increased bone mineral density in postmenopausal women. Denosumab has been shown to decrease hip, vertebral, and nonvertebral fractures [23] compared with low doses of calcium and vitamin D. It appears to be a reasonable alternative for persons whose condition does not improve with bisphosphonates. Renal insufficiency is a listed caution.

\section{Ayurvedic approach for Osteoporosis}

Ayurveda, included here because of the level of acceptance of this form of medicine in India and also other countries. Many studies have proved the success of Ayurveda in management of oral health [24] and the composition of many oral care medications are of plant origin [25-27]. The whole concept of Ayurveda revolves around three energies in the body called doshas namely Vata, Pitta, Kapha. These three energies are called the kinetic or potential energies. A balance between these tridoshas is required to maintain proper health and any imbalance causes ailments [28, 29].

Many ayurvedic medicines have proven to be effective for management of Asthi-majja kshaya [29] i.e., Osteoporosis. Among many, drug of interest here is Laksha Guggul [29, 30] which is a very famous Ayurvedic medicine in tablet form which has Guggulu (commiphora mukul) as its base. It is widely used in the Ayurvedic treatment of bone related diseases and fracture healing. Its major effect on Tridosha is it calms Vata. Also no major complications of it are reported except dose-related.

Composition [29]:

Laksha - Laccifer lacca

Asthisamhari - Cissus quadrangularis

Kakubha - Terminalia arjuna

Ashwagandh - Withania somnifera

Nagabala - Grewia populifol

Guggul - Purified Commiphora mukul

- Laksha is a gum from Ficus religosa tree that heals broken bones.

- Cissus quandrangularis [31] strengthens the bone and has been proved to be having analgesic, antipyretic and anti-inflammatory properties [31-33].

- Arjuna is an astringent and a natural rich source of calcium and helps in quick healing.

- Ashwagandha is a herb which helps in quick healing by improving deposition of calcium on the bones and gives them strength.

- Nagabala improves bone strength and stamina.

Studies have shown Laksha Guggulu [29, 34] has combined effects of bone healing, promoting calcium deposition and is preferred in new and uncomplicated cases of osteoarthritis. Also Lakshadi plaster is used for immobilization and bone healing in case of fractures. The enhanced therapeutic activity demonstrated by Laksha guggulu is mainly due to the synergistic effects of its components as many plant extracts have more disease alleviating functions than isolated compounds. Hence, ayurvedic medicines have been proved successful in management of osteoarthritis and also they promote bone healing which may be even beneficial in case of implant- bone healing??? We suggest studies in this regard which can play a supportive role in implant treatment protocol because lack of depth in scientific studies and reports made the use of these herbals inconclusive.

\section{CONCLUSION}

Successful implant treatment depends on many factors, the more important among them is osseointegration. Studies have shown the time period for osseointegration varying from 3-6 months depending on the location in the jaw, available bone, graft placed, age, medical condition of the patient and factors associated with implant design like the size, shape, texture, surface treatments etc. Many studies focused on modifying these implant related factors so that they can promote bone healing in turn osseotegration.

Pharmacological management of osteoporosis, which is a prevalent bone disorder in many countries and associated with impaired bone healing effecting implant-bone interface have been reviewed with available literature about bisphosphonates, calcitonin, calcium and vitamin D supplementation, estrogen replacement therapies, and ayurvedic medicine Laksha guggulu. Therefore, osteoporosis being one of the risk factor for implant placement should be managed accordingly with pharmacological agents while considering the implant factors and the role of multidisciplinary approach should never be underestimated and more studies are suggested in this respect.

\section{REFERENCES}

1. Dental Implants Facts and Figures. (2011). AAID.

2. Branemark, R., Branemark, P. I., Rydevik, B., \& Myers, R. R. (2001). Osseointegration in skeletal reconstruction and rehabilitation: a review. Journal of rehabilitation research and development, 38(2), 175-182.

3. Puleo, D. A., \& Nanci, A. (1999). Understanding and controlling the bone-implant interface. Biomaterials, 20(23-24), 2311-2321.

4. Davies, J. E. (2003). Understanding peri-implant endosseous healing. Journal of dental education, 67(8), 932-949.

5. Tamimi, F., \& Wu, X. (2017). Osseointegration Pharmacology. JDR Clinical \& Translational Research, 2(3), 211-213.

6. Ouanounou, A., Hassanpour, S., \& Glogauer, M. (2016). The influence of systemic medications on osseointegration of dental implants. J Can Dent Assoc, 82(g7), 1488-2159. 
Keerthi GK et al; Saudi J Oral Dent Res, June, 2020; 5(6): 262-265

7. NIH Consensus Development Panel on Osteoporosis Prevention, Diagnosis, and Therapy. Osteoporosis prevention, diagnosis, and therapy. 2001. JAMA. 285:785-95.

8. Sözen, T., Özışık, L., \& Başaran, N. Ç. (2017). An overview and management of osteoporosis. European journal of rheumatology, 4(1), 46-56.

9. Jaffin, R. A., \& Berman, C. L. (1991). The excessive loss of Branemark fixtures in type IV bone: a 5- year analysis. Journal of periodontology, 62(1), 2-4.

10. Marco, F., Milena, F., Gianluca, G., \& Vittoria, O. (2005). Peri-implant osteogenesis in health and osteoporosis. Micron, 36(7-8), 630-644.

11. Kate, M. A., Palaskar, S., \& Kapoor, P. (2016). Implant failure: A dentist's nightmare. Journal of Dental Implants, 6(2), 51-56.

12. Alsaadi, G., Quirynen, M., Komárek, A., \& Van Steenberghe, D. (2007). Impact of local and systemic factors on the incidence of oral implant failures, up to abutment connection. Journal of clinical periodontology, 34(7), 610-617.

13. Montes, C. C., Pereira, F. A., Thome, G., Alves, E. D. M., Acedo, R. V., de Souza, J. R., ... \& Trevilatto, P. C. (2007). Failing factors associated with osseointegrated dental implant loss. Implant dentistry, 16(4), 404-412.

14. Lewiecki, E. M. (2010). Bisphosphonates for the treatment of osteoporosis: insights for clinicians. Therapeutic advances in chronic disease, 1(3), 115-128.

15. Marx, R. E. (2003). Pamidronate and zoledronate induced avascular necrosis of the jaws: a growing epidemic. Journal Oral Maxillofac Surgery. 61(9):1115-1117.

16. Fugazzotto, P. A., Lightfoot, W. S., Jaffin, R., \& Kumar, A. (2007). Implant placement with or without simultaneous tooth extraction in patients taking oral bisphosphonates: postoperative healing, early follow- up, and the incidence of complications in two private practices. Journal of periodontology, 78(9), 1664-1669.

17. Jeffcoat, M. K. (2006). Safety of oral bisphosphonates: controlled studies on alveolar bone. International Journal of Oral \& Maxillofacial Implants, 21(3): 349-353.

18. Grant, B. T., Amenedo, C., Freeman, K., \& Kraut, R. A. (2008). Outcomes of placing dental implants in patients taking oral bisphosphonates: a review of 115 cases. Journal of Oral and Maxillofacial Surgery, 66(2), 223-230.

19. Madrid, C., \& Sanz, M. (2009). What impact do systemically administrated bisphosphonates have on oral implant therapy? A systematic review. Clinical oral implants research, 20, 87-95.

20. Michael, J., Brian, K. U., \& Mark, H. G. (2015). Diagnosis and Management of Osteoporosis. Am Fam Physician. 92(4):261-8
21. MacLean, C., Newberry, S., Maglione, M., McMahon, M., Ranganath, V., Suttorp, M., ... \& Desai, S. B. (2008). Systematic review: comparative effectiveness of treatments to prevent fractures in men and women with low bone density or osteoporosis. Annals of internal medicine, 148(3), 197-213.

22. Overman, R. A., Borse, M., \& Gourlay, M. L. (2013). Salmon calcitonin use and associated cancer risk. Annals of Pharmacotherapy, 47(12), 1675-1684.

23. Cummings, S. R., Martin, J. S., McClung, M. R., Siris, E. S., Eastell, R., Reid, I. R., ... \& Kutilek, S. (2009). Denosumab for prevention of fractures in postmenopausal women with osteoporosis. New England Journal of Medicine, 361(8), 756-765.

24. Amruthesh, S. (2003). Dentistry and Ayurveda-I. Indian J Dent Res, 14: 1-5.

25. Amruthesh, S. (2003). Dentistry and Ayurveda-II. Indian J Dent Res, 2003;14:132-40.

26. Amruthesh, S. (2007). Dentistry and Ayurveda-III. Indian J Dent Res, 18:112-19.

27. Amruthesh, S. (2008). Dentistry and ayurveda IV: Classification and management of common oral diseases. Indian Journal Dent Res, 19:52-61.

28. Amruthesh, S. (2011). Dentistry \& Ayurveda VAn evidence based approach. International Journal of Clinical Dental Science, 2(1):3-9.

29. Rajoria, K., Singh, S. K., Sharma, R. S., \& Sharma, S. N. (2010). Clinical study on Laksha Guggulu, Snehana, Swedana \& traction in osteoarthritis (knee joint). Ayu, 31(1), 80-87.

30. Mangal, A., Shubhasree, M. N., Devi, P., Jadhav, A. D., Prasad, S. A., Kumar, K., ... \& Dhiman, K. S. (2017). Clinical evaluation of Vatari guggulu, Maharasnadi kwatha and Narayan taila in the management of osteoarthritis knee. Journal of Ayurveda and integrative medicine, 8(3), 200-204.

31. Raj, S. J., \& Joseph, B. (2011). Pharmacognostic and traditional properties of Cissus quadrancularis Linn-An overview. International Journal of Pharma and Bio Sciences2011, 2(1), 131-9.

32. Udupa, K. N., \& Prasad, G. C. (1964). Further studies on the effect of cissus quadrangularis in accelerating fracture healing. The Indian journal of medical research, 52(1), 26-35.

33. Deka, D. K., Lahon, L. C., Saikia, J., \& Mukit, A. (1994). Effect of Cissus quadrangularis in accelerating healing process of experimentally fractured radius-ulna of dog: a preliminary study. Indian J Pharmacol, 26(1), 44-45.

34. Dudhamal, T. S., Mahanta, V. D., \& Gupta, S. K. (2012). Efficacy of Lakshadi Plaster and Laksha Guggulu in the Management of Bhagna (Stable Colle's Fracture) Case Report. International Journal of Ayurvedic Medicine, 3(2), 124-129. 